\title{
Clinical Reasoning: Accumulating endocrinopathies in a car salesman
}

Luuk Wieske, MD, PhD, Ulrich Beuers, MD, and Matthijs C. Brouwer, MD, PhD

Neurology ${ }^{\circledR}$ 2018;90:e1720-e1723. doi:10.1212/WNL.0000000000005478

Correspondence

Dr. Wieske

I.wieske@amc.uva.nl

\section{Section 1}

A 65-year-old man working as a car dealer was referred to our neurology outpatient clinic because of a pituitary mass. Two years before referral, the patient had developed symptoms of polyuria and polydipsia, decreased endurance while working out, fatigue, loss of body hair, and erectile dysfunction. The endocrinologist found hypogonadotropic hypogonadism, hypocortisolism, and central diabetes insipidus, which was treated with testosterone, hydrocortisone, and desmopressin, resulting in adequate control of his symptoms. He did not report symptoms of headache, decreased vision, or neurologic deficits. An MRI of the pituitary gland was performed and showed an enlarged gland and stalk with gadolinium enhancement (figure 1).

The patient's medical history included appendicitis, but otherwise he had been well up to 6 years prior to presentation. At that time, he developed prostatitis that resolved spontaneously. One year later, he developed pancreatitis with secondary endocrine and exocrine insufficiency. Because of presumed alcohol abuse, a diagnosis of alcoholic pancreatitis was made even though the patient categorically denied excessive alcohol intake. He was treated with pancreatic enzyme replacement therapy and oral antidiabetic medication. Four years prior to presentation, he developed salivary gland enlargement that resolved spontaneously. Upon neurologic examination, no abnormalities were found, including normal visual field testing to confrontation.

\section{Question for consideration:}

1. What is the most likely diagnosis and differential diagnosis?

Figure 1 MRI series of the pituitary gland

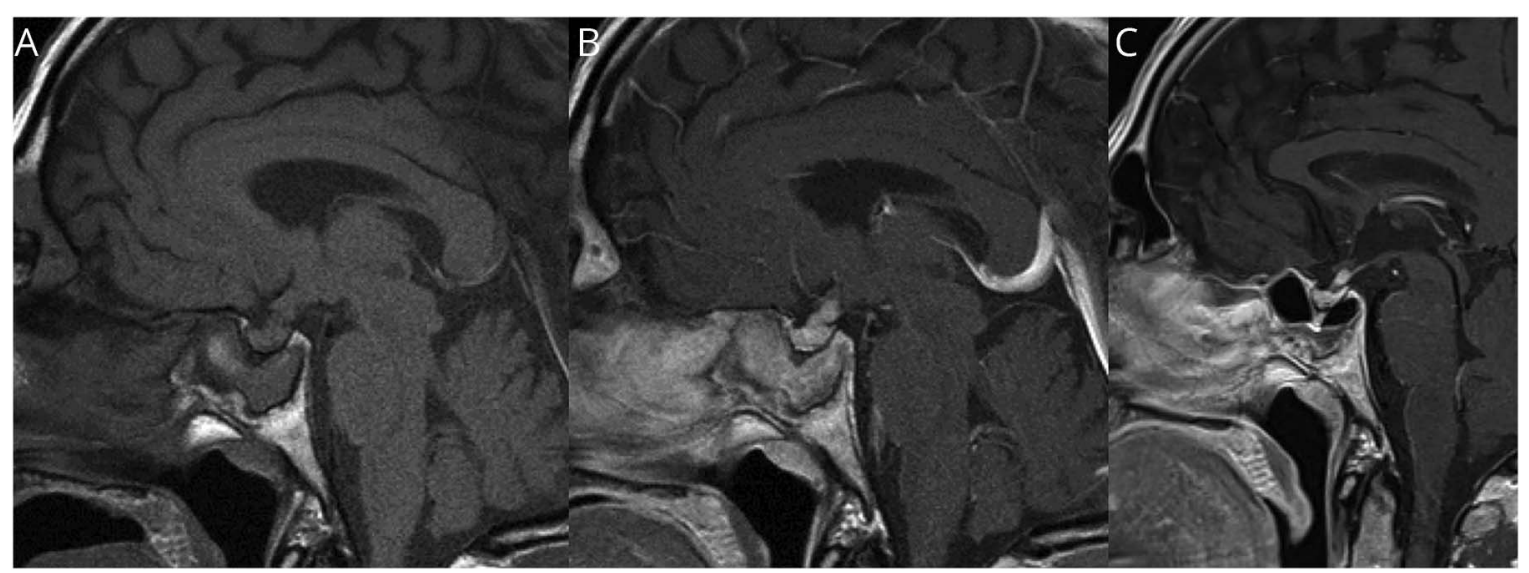

T1-weighted sagittal MRI series of the pituitary gland without (A) and with (B) gadolinium contrast before start of treatment and (C) with gadolinium contrast after 1 year of treatment.

\section{GO TO SECTION 2}

From the Departments of Neurology (L.W., M.C.B.) and Gastroenterology and Hepatology (U.B.), Academic Medical Center, University of Amsterdam; and Centre of Infection and Immunity Amsterdam (CINIMA) (M.C.B.), the Netherlands.

Go to Neurology.org/N for full disclosures. Funding information and disclosures deemed relevant by the authors, if any, are provided at the end of the article. 


\section{Section 2}

The MRI shows diffuse enlargement of the pituitary and pituitary stalk with enhancement after administration of gadolinium contrast. Prior to establishing a differential diagnosis, the critical question in this case whether the patient's previous and current symptoms are part of one unifying diagnosis or should be considered separately needs to be answered first. The patient convincingly persisted in denying excessive amounts of alcohol use, which made the diagnosis of alcoholic pancreatitis as a separate disorder less likely and suggests that the pancreatitis should be added to the list of symptoms, notwithstanding that alcohol intake is frequently underreported by patients. Based on the combination of manifestations in pancreas, salivary glands, prostate, and pituitary gland, and the chronic progressive course with spontaneous improvements, the most likely diagnosis is IgG4-related disease (IgG4-RD). The differential diagnosis for (isolated) pituitary dysfunction and the abnormalities on MRI constitute primary lymphocytic hypophysitis and sarcoidosis. Anti-Ma2-associated encephalitis, tuberculosis, Langerhans cell histiocytosis, lymphoma, and metastatic cancer are less likely because of the chronic course of symptoms and the absence of other neurologic symptoms. Erdheim-Chester disease has a chronic course and may also cause a chronic pituitary dysfunction but the absence of pain caused by bone involvement makes this diagnosis less likely. The radiologic appearance is not typical of a craniopharyngioma or pituitary macroadenoma, which are characteristically heterogeneous on $\mathrm{T} 1$ images showing cysts, necrosis, or hemorrhage.

\section{Question for consideration:}

1. What further investigations are necessary?

GO TO SECTION 3 


\section{Section 3}

For a diagnosis of IgG4-RD, histopathologic confirmation should always be attempted. ${ }^{1}$ Exceptions are for pancreatic manifestations, i.e., autoimmune pancreatitis type I, in which in some cases the presentation and imaging can be regarded as diagnostic, and for pituitary manifestations. ${ }^{1,2}$ IgG4-RD often responds well to treatment, which makes pituitary biopsy with the associated risks a less attractive option. Alternative criteria have therefore been reported for IgG4-related hypophysitis that enable a diagnosis in patients with pituitary or pituitary stalk abnormalities on MRI and (1) a biopsy-proven manifestation of IgG4-RD elsewhere or (2) a raised serum IgG4 level $(>140 \mathrm{mg} / \mathrm{dL})$ and a favorable response to glucocorticoids (i.e., shrinkage of MRI abnormalities and symptom improvement). ${ }^{2}$ IgG4 can also be studied in CSF. ${ }^{3}$ It should be emphasized that increased IgG4 levels are neither specific nor sensitive for IgG4-RD. ${ }^{1}$

To investigate the most likely differential diagnoses in our patient, pulmonary imaging and laboratory studies (serum IgG4, angiotensin-converting enzyme [ACE], and lysozyme) should be done as a first step. In case of sarcoidosis, pulmonary imaging may reveal lymph node involvement and increased ACE or lysozyme levels, although these findings are neither sensitive nor specific and histopathologic studies may be needed to confirm sarcoidosis. A definitive diagnosis of primary lymphocytic hypophysitis can also only be made upon histopathologic investigation. In our patient, serum IgG4 levels were raised $\times 10$ the upper limit of normal (1,360 mg/dL). Pulmonary imaging,
ACE, and lysozyme levels were normal. Based on these findings, additional studies like CSF and biopsy were not pursued and a working diagnosis of IgG4-RD was made.

IgG4-RD is a chronic autoimmune disorder in which men are more frequently affected and the mean age at diagnosis is 67 years. ${ }^{1}$ Many different organ manifestations are possible in isolation or combination, making a diagnosis difficult. Neurologic manifestations are uncommon in IgG4-RD and include pachymeningitis sometimes leading to parenchymal involvement, intraparenchymal, meningeal, orbital, or sinus inflammatory masses (pseudotumors), possibly (multifocal) neuropathy, and hypophysitis. ${ }^{4}$ IgG4-related hypophysitis is a recently described manifestation that is probably rare, although the incidence has not been systemically evaluated. ${ }^{5}$ In a retrospective study, approximately $40 \%$ of cases previously diagnosed as primary lymphocytic hypophysitis were shown to be manifestations of IgG4-RD after reassessment of biopsies, indicating the growing awareness of this diagnosis. ${ }^{6}$ The etiology of IgG4-RD is unknown. One hypothesis states an antigendriven immune response is responsible. Environmental or occupational toxins may be one of the triggers of this immune response. Interestingly, an overrepresentation of blue-collar workers exposed to possible occupational toxins was reported in a cohort of patients with IgG4-RD. ${ }^{7}$ Besides working as car salesman, our patient also worked as a car mechanic.

\section{Question for consideration:}

1. How should this patient be managed? 


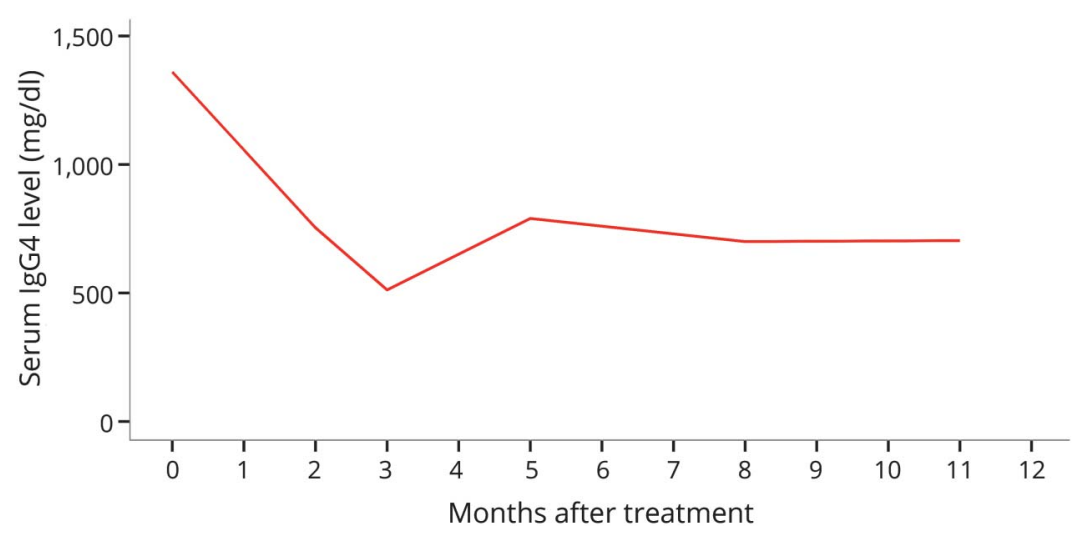

\section{Section 4}

Only 1 randomized controlled trial has been performed guiding therapeutic options for patients with IgG4-RD. ${ }^{8}$ Most patients respond well to glucocorticoids, which is considered first-line treatment. As stated before, a favorable response to glucocorticoids is part of the diagnostic criteria of IgG4-related hypophysitis. This is not specific for IgG4-RD; sarcoidosis may also show a rapid response to glucocorticoids. No response to glucocorticoids should alert the clinician to reconsider the diagnosis although not all manifestations of IgG4-RD respond well to glucocorticoids depending on the degree of fibrosis in the affected organ. ${ }^{1}$ Specific to this case, a pituitary biopsy should be considered when glucocorticoids fail as this may reveal another diagnosis, like Erdheim-Chester disease, which is unresponsive to glucocorticoids, or confirm IgG4-RD and provide justification for starting second-line treatment. No specific regimens concerning dose and speed of tapering have been investigated. Some advocate a starting prednisolone dose of $0.6-1 \mathrm{mg} / \mathrm{kg} / \mathrm{d}$. ${ }^{1}$ The efficacy of second-line immunosuppressants, like azathioprine, mycophenolate mofetil, and methotrexate, has not been investigated in IgG4-RD. These agents are used when the disease is not adequately controlled by glucocorticoid monotherapy or when glucocorticoids cannot be tapered. ${ }^{1}$ In addition, B-cell depletion through rituximab has been described. ${ }^{1}$ In our patient, we started oral prednisone $(20 \mathrm{mg})$, after which serum IgG4 levels (figure 2) decreased but did not normalize. IgG4 levels frequently do not normalize after treatment and may not increase in case of relapse and therefore should only be used as a supportive measure in monitoring patients. ${ }^{1}$ Azathioprine was added because long-term treatment was deemed likely. After an allergic reaction, azathioprine was substituted by mycophenolate mofetil. After 1 year of treatment, the patient is stable and abnormalities on MRI improved, showing less enhancement (figure 1C).

\section{Author contributions}

Dr. Wieske contributed to study concept and design, acquisition of data, analysis and interpretation, and critical revision of the manuscript for important intellectual content. Dr. Beuers contributed to acquisition of data, analysis and interpretation, and critical revision of the manuscript for important intellectual content. Dr. Brouwer contributed to study concept and design, analysis and interpretation, critical revision of the manuscript for important intellectual content, and study supervision.

\section{Study funding}

No targeted funding reported.

\section{Disclosure}

The authors report no disclosures relevant to the manuscript. Go to Neurology.org/N for full disclosures.

\section{References}

1. Kamisawa T, Zen Y, Pillai S, Stone JH. IgG4-related disease. Lancet 2015;385: $1460-1471$.

2. Leporati P, Landek-Salgado MA, Lupi I, Chiovato L, Caturegli P. IgG4-related hypophysitis: a new addition to the hypophysitis spectrum. J Clin Endocrinol Metab 2011;96:1971-1980.

3. Della-Torre E, Galli L, Franciotta D, et al. Diagnostic value of IgG4 indices in IgG4-related hypertrophic pachymeningitis. J Neuroimmunol 2014;266: $82-86$

4. Baptista B, Casian A, Gunawardena H, D'Cruz D, Rice CM. Neurological manifestations of IgG4-related disease. Curr Treat Options Neurol 2017;19:14.

5. Shikuma J, Kan K, Ito R, et al. Critical review of IgG4-related hypophysitis. Pituitary 2017;20:282-291.

6. Bernreuther C, Illies C, Flitsch J, et al. IgG4-related hypophysitis is highly prevalent among cases of histologically confirmed hypophysitis. Brain Pathol 2017;27:839-845.

7. de Buy Wenniger LJM, Culver EL, Beuers U. Exposure to occupational antigens might predispose to IgG4-related disease. Hepatology 2014;60:1453-1454.

8. Masamune A, Nishimori I, Kikuta K, et al. Randomised controlled trial of long-term maintenance corticosteroid therapy in patients with autoimmune pancreatitis. Gut 2017;66:487-494. 


\section{Neurology}

\section{Clinical Reasoning: Accumulating endocrinopathies in a car salesman}

Luuk Wieske, Ulrich Beuers and Matthijs C. Brouwer

Neurology 2018;90;e1720-e1723

DOI 10.1212/WNL.0000000000005478

\section{This information is current as of May 7, 2018}

\section{Updated Information \& Services}

\section{References}

Subspecialty Collections

Permissions \& Licensing

Reprints including high resolution figures, can be found at: http://n.neurology.org/content/90/19/e1720.full

This article cites 8 articles, 1 of which you can access for free at: http://n.neurology.org/content/90/19/e1720.full\#ref-list-1

This article, along with others on similar topics, appears in the following collection(s):

Autoimmune diseases

http://n.neurology.org/cgi/collection/autoimmune_diseases

Endocrine

http://n.neurology.org/cgi/collection/endocrine

Gastrointestinal

http://n.neurology.org/cgi/collection/gastrointestinal

Information about reproducing this article in parts (figures,tables) or in its entirety can be found online at:

http://www.neurology.org/about/about_the_journal\#permissions

Information about ordering reprints can be found online:

http://n.neurology.org/subscribers/advertise

Neurology ${ }^{\circledR}$ is the official journal of the American Academy of Neurology. Published continuously since 1951, it is now a weekly with 48 issues per year. Copyright () 2018 American Academy of Neurology. All rights reserved. Print ISSN: 0028-3878. Online ISSN: 1526-632X.

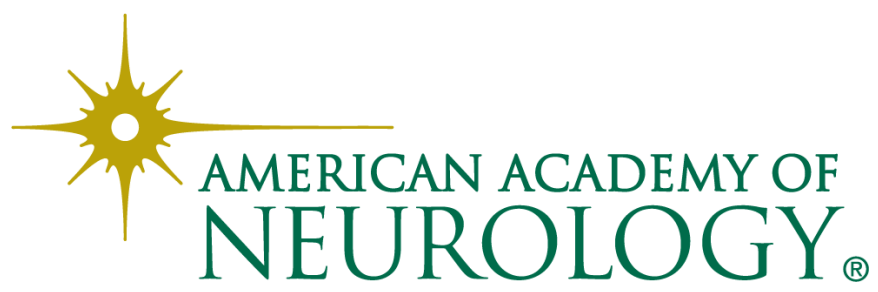

